\title{
Jimo Geothermal Water Management - Existing Challenges and Solutions
}

(Jimo Water Conservancy Bureau.Jimo City, Shandong Province, 266200)

Jimo City is located in the Southwest area of Shandong peninsula, neighbors the Yellow Sear in the east, Lalshan Mountain in the south. It was an county in Qin dynasty and became an city in Sui dynasty1. Jimo city is an coastal city with a long history, which includes 7 towns, 7 subdistricts, 1 provincial economic development zone and 1 provincial tourism resort. Jimo City is located latitude at $120^{\circ} 07^{\prime}-121^{\circ} 23^{\prime}$ east, 36 $\circ 18^{\prime}-36^{\circ} 37^{\prime}$ north . The city's total land area is 1780 square kilometers, the sea area of 2517 square kilometers, the coastline of $183 \mathrm{~km}$ long, $1120000 \mathrm{mu}$ of arable land, population 11300002 , is the core of Shandong blue economy, Qingdao Blue Silicon Valley, ranked China's county economy and county basic competitiveness Top nine county. 3

\section{The Basic Situation}

Jimo Hot Springs Geothermal resources are located in Jimo City Wenquan Town Government resident, east of hot springs village south. Since 1958, there have been the Ministry of Geology, Ocean Research Institute, the Provincial Bureau of Geology and Mineral Resources, Qingdao Geological Engineering Investigation
Institute and other relevant departments have repeatedly organized the thermal geothermal resources exploration, investigation, the formation of a more detailed survey results. Over the years, these achievements have been hot springs geothermal resources development and utilization of basic information, but also higher authorities in charge of approval, management of geothermal resources, an important basis. According to the "Geothermal Resources Census Report4" in the hot spring area of Jimo City, Shandong Province, the geothermal field is located at $120^{\circ} 38^{\prime} 52.4$ " $-120^{\circ} 39^{\prime} 23.8^{\prime \prime}$ east latitude, $36^{\circ} 26^{\prime} 23.1$ " -36 - 26'45.4" north latitude, the Geothermal field area is about 0.34 square kilometers, and the geothermal area is 0.18 square kilometers5 (refers to 0.34 square kilometers can play hot water, but only 0.18 square kilometers within the hot water to reach the bath, the temperature, the other area due to water temperature Too low, no mining value), the average daily water consumption of about 1800 cubic meters6.

\section{The Development and Utilization of the Status}

From the fifties of last century,
Abstract: This article gives a brief introduction of the basic information and current utilize status of the geothermal resource in Jimo, identifies the existing main challenges, thus provides pertinent solutions.

Key words: Geothermal water, Management, Challenge, Solution.

Published on 30th Sept,2017

Corresponding Author: Lan Xu-shi, Jimo Water Conservancy Bureau, No. 1199, Ao'lan Road, Jimo City, Shandong Province, 266200, China. jimolanlan@126.com.15131753667 
relevant units and units of the state, province, Qingdao City, has built a number of nursing homes in Wenquan town, mainly use the geothermal water to convalescence, treatment, but not much water, such as Qingdao workers sanatorium, tax sanatorium, Qingdao food system workers sanatorium, Qingdao hot spring sanatorium, supply and marketing Social sanatorium, 61680 troops sanatorium, China Petroleum Physics Exploration Bureau Hot Spring Resort, Qingdao Hot Spring Hospital $^{7}$. Since the mid-late 1990s, especially in recent years, Wenquan town and the surrounding area development and construction speed, geothermal resources consumption is also increasing. At present, there are seven enterprises with hot spring water: Hong Kong China Travel (Qingdao) Haiquan Bay Co., Ltd., Qingdao Shenghai Hot Spring Hotel Investment Management Co., Ltd. City Investment Hot Spring Resort, Qingdao Xianggan Hotspring Resort Management Co., Ltd., Qingdao Jimo Hot Spring Kirin Villa Co., Ltd., Qingdao Tiantai Hot Spring Golf Development Co., Ltd., Patong Township (Qingdao Zhongtian Jiahe Property Co., Ltd.), Bank of China (Shandong Branch of China Bank Co., Ltd. $)^{8}$.

\section{The main problems}

In recent years, Jimo municipal government introduced a number of measures to strengthen the management of hot springs geothermal water resources, but there are still some problems.

First, the management unit did not really perform the function, still using extensive management. In May 2005, Jimo City issued the Notice on Printing and Distributing the Provisions on the Administration of Geothermal Water Resources in Jimo City (that is, Zengfa [2005] No. 18), the development, utilization, management and protection of geothermal water resources Breach of the relevant provisions of the legal liability should be described in detail. In August 2008, Jimo City issued the "Notice on the Establishment of the Geothermal Resource Management Office of Jimo City" (ie, No. 6 [2008]), which set up a geothermal resource management office, which is responsible for geothermal resources planning and daily Development, inspection activities of the supervision and management work. In the actual work process, the geothermal resources management office did not really perform the function, but only seven enterprises of the geothermal wells were acquired, but the East Hot Springs Village, 59 individual bath business households did not purchase, nor closed wells, still There is a disorderly development state.

Second, did not carry out effective replenishment sources, geothermal water can be reduced by year. At present, Qingdao Hot Spring Geothermal Development Co., Ltd. and 59 individual bath business households in East Wenquan Village for many years only to take water, failed to organize scientific and reasonable recharge source, resulting in hot spring water temperature decreased year by year, the water temperature decreased year by year.

Third, the degree of hot spring water recycling is not high. At present, Jimo City, the use of hot spring water companies have not taken recycling, after the use of a discharge that is hot, hot spring hot water waste is serious.

Fourth, the waste water is not all into the pipe network, the local water environment caused by some pollution. According to the Jimo City Environmental Protection Bureau detection, some of the individual business households abandoned water is not unified discharge to the municipal sewage pipe network, and some directly discharged into the river, the river caused a certain pollution' .

\section{Solution}

(1) Strengthen the centralized management, to avoid the hot springs of hot water disorderly mining. Geothermal resources management office should coordinate public security, land, water conservancy, environmental protection and hot spring streets and other units, to develop a reasonable compensation standards, 59 individual bath business households in East Wenquan Village unified acquisition, the original wells to fill. At the same time, increase the unauthorized drilling hot springs geothermal wells management efforts, announced the call, the illegal drilling wells to be investigated and dealt with, seized drilling equipment, asked to immediately fill back fillers, and accountability of the parties, so as to effectively prevent unauthorized play Well the problem occurred.

(2) Strictly implement the water permit system and plan water management. Jimo hot spring is a rare resource, reserves are limited, in recent years, with some use of geothermal resources projects settled in hot springs town, the relative increase in mining capacity, the groundwater level is declining trend, increase the hot spring hot water management is inevitable Row. Therefore, it is necessary to strengthen the management of Qingdao Hot Spring Geothermal Development Co., Ltd. according to law, and implement the total control of the annual exploitation of geothermal water, and firmly control it to allow reasonable exploitation.

(3)Play the role of price leverage to promote water conservation. April 1, 2016, Jimo City Price Bureau of urban water supply prices were adjusted, tap water to 16 yuan / ton, 
hot springs geothermal water resources is a rare resource, and now 10 yuan / cubic meters of hot water prices significantly Low, it should be adjusted to 2-3 times the price of water bath water prices. At the same time, strict implementation of the planned water, the super-planned water doubled water charges, through the price of leverage to limit the excessive exploitation of geothermal water.

(4)Increase capital investment, improve the degree of geothermal water recycling. It is understood that Changchun Guoxin Nanshan Hot Spring Hotel invested more than 1,000 million, using the German water treatment equipment for the use of geothermal water to provide strong technical support. The use of this equipment on the use of geothermal water after filtration, heating, re-use, by a very good effect. Qingdao Hot Springs Geothermal Development Co., Ltd. should increase capital investment, improve the capacity of water treatment facilities, and actively explore the hot and humid hot water resources recycling path, to minimize the exploitation of geothermal water to ensure the sustainable use of hot spring hot water.

(5)To strengthen the management of hot spring wastewater, reduce water pollution. In strict accordance with the relevant provisions and standards for the disposal of water disposal units of water units, requiring all the use of geothermal water units and individuals must implement a good sewage treatment program to ensure that discharge standards, and regular inspection and inspection from time to time. Non-compliance of the enterprise, not to supply hot water; on the non-compliance of the individual business households, strengthen management, deadline for rectification ${ }^{10}$.

\section{References}

[1] Jimo Zhi, Jimo Shi Office, 2003, 5 ;

[2] Statistical yearbook of Jimo in 2017, Jimo Municipal Bureau of Statistics , 2017, 5;

[3] Top 100 white paper on county economy in China in 2017, CCID County Economic Research Center,2017,7;
[4] General survey of geothermal resources in Wenquan Town, Jimo, Bureau of Geology and mineral resources of Shandong,1960,3;

[5] luan guang zhong, cao li hua, wang wen zheng, Hot water sediment indicator and its significance in Jimo hot spring basin, Qingdao, Journal of Ocean University of China,2005,5;

[6] liu yan guang, cao xiu yun, fu yun xia, wu shi ying, Dynamic characteristics of geothermal water quality in Jimo hot spring, Shandong land resources,2010,2;

[7] Jimo water conservancy records, Jimo Water Conservancy Bureau,2003,3;

[8] Investigation and evaluation of water resources development and utilization in Jimo, Jimo Water Conservancy Bureau,2006,3;

[9] Investigation and evaluation of water resources in Jimo, Jimo Water Conservancy Bureau,2006,3;

[10] zhu xiao rong, Investigation report of hot spring resources in Dandong area,2012,6. 